\title{
Advancing Motor Learning and Development Research: A New Era for Our Journal
}

\author{
Maarten A. Immink \\ Flinders University
}

As the incoming Editor-in-Chief of the Journal of Motor Learning and Development (JMLD), I take the helm of a thriving journal entering a new era as it approaches its 10th year. I would like to take this opportunity to acknowledge the excellent leadership of Daniella Corbetta as the Journal's second Editor-in-Chief. I also would like to point out that recent strong journal performance presents several promising opportunities as JMLD approaches the start of a second decade.

This second issue of the ninth volume marks the completion of Daniela Corbetta's 6-year tenure as Editor-in-Chief. Her commitment, dedication, and effective leadership of the Editorial Board has translated into several noteworthy achievements, including an increase in annual citations and journal h-index. Importantly, under Daniela's leadership, JMLD has established a sustainable publication rate with three-issue volumes since 2018.

In March, the Editorial Office received notice that the Journal will be indexed in the Web of Science Core Collection as part of the Emerging Sources Citation Index. It is anticipated that the Journal's content will be available in the Web of Science by the Fall of this year. This is a momentous step forward for the Journal to increase its exposure, attract high-quality submissions, and establish journal prestige through eventual receipt of an impact factor. It is important to recognize that this achievement is the result of a collective scholarly community effort and collaboration from: Daniela, the JMLD Editorial Board, our support staff at Human Kinetics, the peer reviewers who generously provide their time and expertise, and most importantly, our colleagues who have published their ideas, theorical advances, and empirical evidence within the Journal.

As one of the official journals of the North American Society for Psychology of Sport and Physical Activity (NASPSPA), JMLD is an extension of the Society's mission to develop, advance, disseminate, and improve the quality of research in motor learning and development. Advancing the partnership between the Journal and the Society presents a mutually beneficial opportunity. NASPSPA members

Immink (maarten.immink@flinders.edu.au) is the new Editor-in-Chief of the Journal of Motor Learning and Development, and is with the College of Nursing and Health Sciences, Flinders University, Adelaide, Australia. 
provide expertise on the Journal's Editorial Board and peer-review process and the Journal's publications. In turn, for the NASPSPA community, the Journal offers a "home" for motor learning and developing scholarly work. In this sense, JMLD provides a destination where Society scholars can disseminate their work and establish a repository of ideas, theory, evidence, and applications.

JMLD also represents a forum for exchange of Society members' ideas, development of emerging areas, and address of research challenges. NASPSPA is well known for the sense of connection it provides its membership, including through the annual conference and initiatives such as the teaching network and online research seminar series. As an extension of the NASPSPA community, the Journal aims to strengthen existing connections and promote new connections to support the Society's mission of advancing motor learning and motor development research fields. Opportunities to advance the disciplines within the Journal include promoting motor learning and development transdisciplinary research, relating research to contemporary society needs, translating research into practice, and establishing rationale for growth in motor learning and development research funding. Finally, JMLD offers NASPSPA an opportunity to connect with the world, including motor learning and development scholars or practitioners who might become aware of the Society and be drawn to joining the Society through the content NASPSPA members publish in the Journal.

Staying with the theme of connection, the Journal is well-placed to connect a wide audience to motor learning and development research. The Journal has been actively involved in establishing its presence on social media through its Social Media Manager, Harjiv Singh at the University of Nevada-Las Vegas. One initiative has involved raising the Journal's profile on Twitter (@JMLDjournal). This profile has drawn attention to JMLD through establishing an international following that receives news about publications, research, and reviewer excellence awards as well as NASPSPA conference events. The Journal will continue to leverage web and social media platforms to increase its outward facing profile and to support dissemination of motor learning and development science. An effective internet and social media presence represents opportunities to increase publication impact both through formal research citations but also broader social influence impact based on faster web indicators such as Twitter mentions, altmetrics, PlumX Metrics, Google Scholar metrics, and Mendeley bookmarks (Thelwall \& Kousha, 2015).

The current sustainable rate of publication is indicative of JMLD's standing as a preferred destination for the publication of motor learning and development research. Still, it is important to consider what factors the Journal can leverage to further its position to attract high-quality submissions. A key factor in journal selection is the journal's prestige (Frank, 1994; Suiter \& Sarli, 2019). This is a challenge for a relatively young journal working its way toward an impact factor. However, the challenge of being a young journal is at the same time an opportunity because the impact factor is not the sole reason for why a journal appeals to authors. Other reasons can be collectively described as the author experience. A journal's appeal is also dependent on its peer-review timeline and the perceived likelihood that the peer review will provide useful feedback (Donsbach, Lipset, NoelleNeumann, Traugott, \& Worcester, 2005; Frank, 1994). A positive initial experience with a journal is important as most authors choose to publish within a limited set of journals (Suiter \& Sarli, 2019) and prefer journal's they have previously 
published in (Frank, 1994). As JMLD builds its prestige, there is an opportunity to ensure authors receive a supportive experience, including through an efficient, yet rigorous and constructive peer-review process.

Finally, and equally important, an opportunity to foster Journal growth and advancement of the motor learning and development scientific disciplines lies in growing and strengthening global research connections. JMLD currently includes good international representation. For example, 55\% of Volume 7 (2019) publications were contributed by authors based outside of the United States of America. Thirty-five percent of the current Editorial Board includes scholars based outside of North America with representation from United Kingdom, Western Europe, Asia, South America, and Pacific regions. There is potential to increase the Editorial Board international profile, particularly with discipline scholars based in Africa, Eastern Europe, and the Middle East regions. Their representation in the Journal's leadership can offer effective solutions to increase visibility of discipline-related research conducted by our colleagues in traditionally underrepresented countries.

Although advancement of motor learning and development science is a global effort, research from some countries lacks visibility within the global research community (Salager-Meyer, 2014) because authors based in these countries may tend to publish in local scholarly journals with a lack of indexing and restricted range of dissemination (Arunachalam, 2004). Not surprisingly, 2020 Scimago Country Rank data for the Experimental and Cognitive Psychology subject category (https://www.scimagojr.com/countryrank.php?category $=3205 \&$ area $=3200 \&$ year $=2020$ ), indicates that $87 \%$ of indexed publications came from authors based in $20 \%$ of the listed countries. By supporting inclusivity and embracing the diversity of global research in the motor learning and development fields, JMLD can stimulate and enrich our research disciplines, increase scholar visibility, grow research networks and collaborations, and attract new scholars to the NASPSPA community.

\section{References}

Arunachalam, S. (2004). Science on the periphery: Bridging the information divide. In H.F. Moed, W. Glänzel, \& U. Schmoch (Eds.), Handbook of quantitative science and technology research. Dordrecht, Netherlands: Springer. doi:10.1007/1-4020-2755-9_8

Donsbach, W., Lipset, S.M., Noelle-Neumann, E., Traugott, M.W., \& Worcester, R. (2005). Authors' and reviewers' preferences for modes of submitting and reviewing manuscripts. International Journal of Public Opinion Research, 17(4), 395-398. doi:10. 1093/ijpor/edh114

Frank, E. (1994). Authors' criteria for selecting journals. Journal of the American Medical Association, 272(2), 163-164. doi:10.1001/jama.1994.03520020089026

Salager-Meyer, F. (2014). Writing and publishing in peripheral scholarly journals: How to enhance the global influence of multilingual scholars? Journal of English for Academic Purposes, 13, 78-82.

Suiter, A.M., \& Sarli, C.C. (2019). Selecting a journal for publication: Criteria to consider. Missouri Medicine, 116(6), 461-465.

Thelwall, M., \& Kousha, K. (2015). Web indicators for research evaluation. Part 2: Social media metrics. Profesional de la Informacion, 24(5), 607-620. 